\title{
Hotspots of female genital mutilation/ cutting and associated factors among girls in Ethiopia: a spatial and multilevel analysis
}

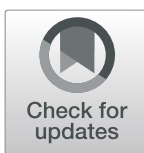

Tesfahun Taddege Geremew ${ }^{1 *}$, Muluken Azage $^{2}$ and Endalkachew Worku Mengesha²

\begin{abstract}
Background: Female genital mutilation/cutting (FGM/C) is a harmful traditional practice that violates the human rights of girls and women. It is widely practiced mainly in Africa including Ethiopia. There are a number of studies on the prevalence of FGM/C in Ethiopia. However, little has been devoted to its spatial epidemiology and associated factors. Hence, this study aimed to explore the spatial pattern and factors affecting FGM/C among girls in Ethiopia.
\end{abstract}

Methods: A further analysis of the 2016 Ethiopia Demographic and Health Survey data was conducted, and a total of 6985 girls nested in 603 enumeration areas were included in this analysis. Global Moran's I statistic was employed to test the spatial autocorrelation, and Getis-Ord Gi* as well as Kulldorff's spatial scan statistics were used to detect spatial clusters of FGM/C. Multilevel logistic regression models were fitted to identify individual and community level factors affecting FGM/C.

Results: Spatial clustering of FGM/C was observed (Moran's I = 0.31, $p$-value $<0.01$ ), and eight significant clusters of FGM/C (hotspots) were detected. The most likely primary SaTScan cluster was detected in the neighborhood areas of Amhara, Afar, Tigray and Oromia regions ( $L L R=279.0, p<0.01)$, the secondary cluster in Tigray region $(L L R=67.3$, $p<0.01)$, and the third cluster in Somali region ( $L L R=55.5, P<0.01)$. In the final best fit model, about $83 \%$ variation in the odds of FGM/C was attributed to both individual and community level factors. At individual level, older maternal age, higher number of living children, maternal circumcision, perceived beliefs as FGM/C are required by religion, and supporting the continuation of FGM/C practice were factors to increase the odds of FGM/C, whereas, secondary or higher maternal education, better household wealth, and regular media exposure were factors decreasing the odds of FGM/C. Place of residency, Region and Ethnicity were also among the community level factors associated with FGM/C.

Conclusions: In this study, spatial clustering of FGM/C among girls was observed in Ethiopia, and FGM/C hotspots were detected in Afar, Amhara, Tigray, Benishangul Gumuz, Oromia, SNNPR and Somali regions including Dire Dawa Town. Both individual and community level factors play a significant role in the practice of FGM/C. Hence, FGM/C hotspots require priority interventions, and it is also better if the targeted interventions consider both individual and community level factors.

Keywords: Genital mutilation/cutting, Circumcision, Spatial, Multilevel

\footnotetext{
* Correspondence: tesfahun.taddege@yahoo.com

${ }^{1}$ Public Health Emergency Management (PHEM) Directorate, Amhara Public Health Institute (APHI), Bahir Dar, Ethiopia

Full list of author information is available at the end of the article
}

(c) The Author(s). 2021 Open Access This article is licensed under a Creative Commons Attribution 4.0 International License, which permits use, sharing, adaptation, distribution and reproduction in any medium or format, as long as you give appropriate credit to the original author(s) and the source, provide a link to the Creative Commons licence, and indicate if changes were made. The images or other third party material in this article are included in the article's Creative Commons. licence, unless indicated otherwise in a credit line to the material. If material is not included in the article's Creative Commons licence and your intended use is not permitted by statutory regulation or exceeds the permitted use, you will need to obtain permission directly from the copyright holder. To view a copy of this licence, visit http://creativecommons.org/licenses/by/4.0/ The Creative Commons Public Domain Dedication waiver (http://creativecommons.org/publicdomain/zero/1.0/) applies to the data made available in this article, unless otherwise stated in a credit line to the data. 


\section{Background}

Female genital mutilation/Cutting (FGM/C), also known as "female circumcision", refers to "all procedures involving partial or total removal of the external female genitalia or other injury to the female genital organs for non-medical reasons" [1]. It is a violation of girls' and women's right to life, right to physical integrity, and right to health, as it damages healthy genital tissue and can lead to severe consequences for girls' and women's physical and mental health $[2,3]$.

FGM/C is associated with adverse health consequences in women over both the short and long terms $[1,4]$. Immediate complications include severe pain, excessive bleeding, shock, difficulty in passing urine, delayed or incomplete healing, and infections, whereas, long-term consequences can include chronic pain, decreased sexual enjoyment, sterility, recurring urinary tract infections, the formation of deride cysts, birth complications, and psychological consequences, such as post-traumatic stress disorder $[1,4,5]$.

Global estimates indicated that more than 200 million women and girls have experienced FGM/C $[6,7]$. In Africa, the prevalence of $\mathrm{FGM} / \mathrm{C}$ is still highly prevalent despite its decline in the last three decades. The prevalence decreased from $57.7 \%$ in 1990 to $14.1 \%$ in 2015 in North Africa, from $73.6 \%$ in 1996 to $25.4 \%$ in 2017 West Africa, and from $71.4 \%$ in 1995 to $8.0 \%$ in 2016 in East Africa [8]. In Ethiopia, the prevalence of FGM/C among girls declined from $24 \%$ in 2005 to $16 \%$ in 2016 [9, 10].

Despite international and national efforts to eliminate the practice of $\mathrm{FGM} / \mathrm{C}$, it has been widely practiced mainly in Africa for various reasons [1, 11]. Reasons that parents give for the procedure include preserving chastity, ensuring marriageability, rite of passage, improving fertility, religious requirement, and enhancing sexual pleasure for men [3]. Also, the practice is often presented as part of a girl's initiation into womanhood within her own particular community, and as a way of controlling women's sexuality [12].

The government of Ethiopia has committed to eliminating the practice of FGM/C by 2025 [13]. However, it is still widely practiced across the communities (16\% among girls aged 0-14 years and 65\% among women aged 15-49 years) [10], and both individual level and community level factors may play an important role in the continuation the practice.

Study findings on FGM/C in Ethiopia have focused solely on prevalence, characteristics of individuals affected and individual level factors associated with FGM/ C [14-19]. The findings of such studies are insufficient and fail to capture the spatial epidemiology and community level factors affecting the practice of FGM/C beyond individual level factors.

In this study, Kulldorff's spatial scan statistic was used since it is widely suggested in detecting appropriate local clusters compared to other spatial analysis techniques [20-22], mainly for two reasons. First, SaTScan can detect a cluster of any size between zero and a maximum limit defined by the user. Second, spatial scan statistic has a higher power of detecting local clusters than other available methods [21, 23]. However, this scan statistic also has limitations: it uses a circular window to define the potential cluster areas and thus has difficulty in correctly detecting actual noncircular clusters. In addition, SaTScan is sensitive to user controlled parameter choices (e.g., the maximum circle size, defined as the percentage of the total population at risk), and produces less usable clusters when inappropriately choosing parameters (i.e., heterogeneous contents). Thus, this study employed both spatial statistical techniques to overcome such problems.

In addition, previous studies identified individual level factors associated with FGM/C using a basic ordinary logistic regression model that has less statistical power, and could not control the nesting effect of clusters at different levels $[14,16,18,19,24]$. Thus, it is better to apply appropriate statistical methods for a more comprehensive and sound analysis to consider the cluster effect using multilevel analysis. Therefore, the study aimed to explore the spatial pattern of FGM/C and associated factors among girls in Ethiopia using a SaTScan spatial and multilevel analysis.

\section{Methods \\ Study settings}

This study was conducted using the data from the 2016 Ethiopia demographic and health survey (EDHS). In Ethiopia, this national and subnational representative household survey is conducted every five years. Being the most populous country in the region, Ethiopia is located in the horn of Africa between 3 and 15 degrees north latitude and 33 and 48 degrees east longitude [25]. Ethiopia is administratively divided into regional states and chartered zones, districts (woreda) and kebeles (the smallest administrative units). For the 2007 Ethiopian population and housing census (PHC), the kebeles were sub-divided into enumeration areas (EAs), which were used as a primary sampling unit for the 2016 EDHS [10].

\section{Study design and period}

A cross-sectional data analysis was conducted using the secondary data from the 2016 EDHS, which was collected from January 18 to June 27, 2016.

\section{Study population and eligibility}

The study population of this study were all girls aged 014 years in the randomly selected enumeration areas (EAs) of Ethiopia. Girls from the EAs with no geographical coordinates were excluded from this study. 


\section{Sampling technique and sample size}

In the 2016 EDHS, data were collected through a stratified, two-stage cluster sampling technique using the complete list EAs for the $2007 \mathrm{PHC}$ as a sampling frame. The primary and secondary sampling units were EAs and households, respectively.

The 2007 PHC had a complete list of 84,915 EAs, and from this sampling frame a total of 645 EAs (202 urban and 443 rural) were selected with probability proportional to EAs size (PPS). In the second stage, 28 households per cluster were selected with an equal probability systematic selection. Overall, 16,650 households were interviewed successfully in this survey, yielding $98 \%$ household response rate. From those interviewed households, 16,583 women in the reproductive age were identified for individual interviews, and 15,683 women were interviewed successfully, yielding a response rate of $95 \%$. Among the household in which the 15,683 women interviewed, 7795 households were selected for FGM/C interviews. By excluding 321 girls from the EAs with no geographic coordinates, 6985 girls aged $0-14$ years were included for this study. The detailed methodology has been published in the 2016 EDHS final report [10].

\section{Data source and extraction}

The datasets used for this study are publicly available in the DHS Program repository (https://www.dhsprogram. com/data/dataset_admin) to all registered users, downloaded with permission. After reviewing and understanding the details of the EDHS data structure and dataset types, we selected the recommended dataset type for girls' circumcision. Data on FGM/C, and its potential explanatory variables (individual and community level variables) were extracted.

\section{Study variables and measurement}

The outcome variable of this study is female genital mutilation/cutting status, and it was measured by asking women who had daughters whether any of their daughters born in 1992 or later had been circumcised. If a girl had been circumcised, the FGM/C status was classified as "Yes", otherwise "No".

\section{Explanatory variables}

As described in Table 1, both individual and community level variables were included as potential explanatory variables of daughter's FGM/C. Individual-level (level I) variables include women's and their daughters' background characteristics, while community-level (level II) variables include the common characteristics of study subjects based on the enumeration areas or clusters within the 2016 EDHS data. Some community level variables-i.e., proportion of community with regular media exposure, proportion of community in the poor wealth quantile, and women's literacy rate were generated by aggregating the individual level data into clusters. Using the proportion of each variable aggregated per cluster, the variables were recoded into "high" and "low" groups based on the national median values. Median values were used to categorize the community level variables as high and low since the aggregated values were not distributed normally (Table 1).

\section{Operational definitions}

Circumcision status of girls: In the 2016 EDHS, women who had daughters were asked if any of their daughters born in 1992 or later had been circumcised. If a girl has been circumcised, she was classified as "Yes", otherwise "No" [10].

Mass media exposure: In the 2016 EDHS, women were asked how often they read a newspaper, listened to the radio, or watched television. Those who responded at least once a week are considered to be regularly exposed to that form of media [10].

Proportion of community with regular media exposure: The community level media exposure was categorized as "high" if the proportion of the communities' regular exposure to mass media is above the national median value, otherwise "low". The proportion was computed by aggregating individual's regular media exposure in cluster.

Proportion of community in the poor wealth quantile: The community level poor wealth index was categorized as "high" if the proportion of the communities in the poor wealth quantile is above the national median value, otherwise "low". The proportion was computed by aggregating individual's wealth index in cluster.

\section{Data management and statistical analysis}

Further recoding of variables was done to better suit with other studies for comparison. Data were analyzed using Stata Version 14 [21] for the non-spatial statistical analysis, and SaTScan v9.6 (https://www. satscan.org) [26] as well as ArcGIS 10.5 (http://www. esri.com) for the spatial analysis. Sampling weights were applied to ensure sample representativeness, and the detailed weighting procedure is found in the EDHS final report [10].

Spatial analysis: To evaluate whether the pattern of FGM/C is clustered, dispersed or random across the whole study area, global spatial autocorrelation was assessed using a global statistic called Moran's I. A positive and statistically significant Moran's I value (positive spatial autocorrelation) indicates the clustering of like values, while a negative and significant Moran's I value (negative spatial autocorrelation) indicates a dispersed pattern [27]. As a positive spatial autocorrelation was explored, Kulldorff's method of Poisson-based purely 
Table 1 Independent variables and categorization

\begin{tabular}{|c|c|}
\hline Variables & Categories \\
\hline \multicolumn{2}{|l|}{ Individual level factors } \\
\hline Age of girl at circumcision (years) & (1) $0-4$; (2) 5-9; (3) 10-14 \\
\hline Mother's age (years) & (1) 15-19; (2) 20-24; (3) 25-29; (4) 30-34; (5) 35-49 \\
\hline Marital status & (1) Married; (2) Divorced; (3) widowed; (4) others \\
\hline Religion & (1) Orthodox; (2) Muslim; (3) Protestant; (4) Others \\
\hline Mother's education & (1) No education; (2) Primary; (3) Secondary or higher \\
\hline Father's education & (1) No education; (2)Primary; (3)Secondary or higher \\
\hline Mother's occupation & (1) Did not work; (2) Non-Professional; (3) Professional \\
\hline Father's occupation & (1) Did not work; (2) Non-Professional; (3) Professional \\
\hline Maternal circumcision status & (1) Circumcised; (2) not circumcised \\
\hline Wealth index & (1) Poorest; (2)Poorer; (3) Rich; (4) Richer; (5)Richest \\
\hline Sex of household head & (1) Male; (2) Female \\
\hline Number of living children & (1) $1-2 ;$ (2) 3-4; (3) 5-6; (4) 7+ \\
\hline Mother's relation to the head of the household & (1) Wife; (2) head; (3) Daughter; (4) Others \\
\hline Had regular media exposure & (0) No; (1) Yes \\
\hline Perceived religious believes to FGM/C & (1) Required; (2) Not required; (3) No religion; (4) Don't know \\
\hline Women's opinions towards the practice of FGM/C & $\begin{array}{l}\text { (2) Should be continued; (2) should not be continued; (3) } \\
\text { Don't know/depends }\end{array}$ \\
\hline Information on FGM/C & (1) Ever heard; (2) Not ever heard \\
\hline \multicolumn{2}{|l|}{ Community level factors } \\
\hline Residence & (1) Urban; (2) Rural \\
\hline Region & $\begin{array}{l}\text { (1) Somali; (2) Tigray; (3) Afar; (4) Amhara; (5) Oromiya; (6) } \\
\text { Benishangul-Gumuz; (7) SNNPR; (8) Gambella; (9) Harari; (10) } \\
\text { Addis Ababa (11) Dire Dawa }\end{array}$ \\
\hline Ethnicity & $\begin{array}{l}\text { (1)Affar; (2) Somali; (3) Amhara; (3) Oromo; (4) Tigray; (5) Sidama; } \\
\text { (6) Wolaita; (7) Guragie; (8) Siltie; (9) Dawuro; (10) Kembata; (11) } \\
\text { Berta (12) Agew Awi; (13) Hadiya; (14) Others }\end{array}$ \\
\hline Proportion of community with regular media exposure & (1) Low; (2) High \\
\hline Women's literacy rate of the community & (1) Low; (2) High \\
\hline Proportion of community in the poor wealth quantiles & (1) Low; (2) High \\
\hline
\end{tabular}

spatial scan statistic was employed to detect the local clusters of areas with high rates of FGM/C using SaTScan 9.6 software [26]. "SaTScan" is a trademark of Martin Kulldorff. The SaTScan ${ }^{\mathrm{TM}}$ software was developed under the joint auspices of (i) Martin Kulldorff, (ii) the National Cancer Institute, and (iii) Farzad Mostashari of the New York City Department of Health and Mental Hygiene [26, 28, 29]".

To detect significant clusters of areas with FGM/C among girls, SaTScan uses a circular window of variable size. The maximum spatial cluster size was set to $25 \%$ of the population at risk, and $p$-values for cluster detection were calculated using standard Monte Carlo hypothesis testing with 999 Monte Carlo replicates. Statistically significant cluster was declared when the log likelihood ratio (LLR) is greater than the Standard Monte Carlo critical value for 0.05 significance level, or p-value $<0.05$ $[26,28]$. In addition, hot spot analysis using the Getis-
Ord $\mathrm{Gi}^{*}$ statistic was carried out to identify $\mathrm{FGM} / \mathrm{C}$ hotspots.

A spatial interpolation was used to predict the level of FGM/C for the unmeasured locations in the country from the limited number of sample data points using an inverse distance weighted (IDW) technique. The IDW tool uses a method of interpolation that estimates the percentage of FGM/C by averaging the values of sample data points in the neighborhood locations.

Multilevel logistic regression analysis: Considering the hierarchical nature of the 2016 EDHS data in which 6985 girls aged 0-14 years were nested within 603 EAs, we fitted multilevel logistic regression models were fitted to identify predictors of FGM/C at individual and community levels. To compare and select the best fit model, four models were fitted: the first model (model I), also called the null model, was fitted without any predictor variable as a base line model, the second model (model 
II) was fitted with variabels at individual level, the third model (Model III) was fitted with variables at community level, and the final model (model IV) was fitted with both individual and community level variables. Then the models were compared using deviance information criteria (DIC), and the final best fit model (model IV) was selected as the model with the smallest DIC value [30].

To declare statistical significance, adjusted odds ratio (AOR) with 95\% confidence interval was used as a measure of association (fixed effect) between the outcome variables and the possible predictor variables. Intra-class correlation coefficient (ICC), proportional change in variance $(\mathrm{PCV})$, and median odds ratio (MOR) were also used as measures of variation (random effects). ICC is a measure of within-cluster variation, the variation between individuals within a cluster and it was calculated as $\quad \mathrm{ICC}=\frac{V_{A}}{V_{A}+\frac{\pi^{2}}{3}}=\frac{V_{A}}{V_{A}+3.29}$, where $\mathrm{V}_{\mathrm{A}}$ is the estimated variance of clusters. It is also used to evaluate whether or not the community level (level 2) variation is ignorable. The PCV, which is frequently used to quantify the variation explained by a multilevel model, expresses the total variation attributed to individual and community level factors, and it was computed as $\mathrm{PCV}=\frac{\mathrm{V}_{\mathrm{A}}-\mathrm{V}_{\mathrm{B}}}{\mathrm{V}_{\mathrm{A}}}$, where $V_{A}$ is the variance of the null model (model 1), and $V_{B}$ is variance of the model with individual or/and community characteristics [31]. MOR is the median odds ratio between the individual at higher risk of the outcome and the individual at lower risk of the outcome when two individuals from two different randomly selected clusters are compared (difference in risk are entirely quantified by the cluster-specific random effects). It was computed using the formula: $M O R=\exp ($ $\left.\sqrt{2 \times V_{\mathrm{A}}} \times 0.6745\right) \approx \exp \left(0.95 \sqrt{\mathrm{V}_{\mathrm{A}}}\right)$, where $\mathrm{V}_{\mathrm{A}}$ is the cluster level variance [31, 32].

\section{Ethical consideration}

Ethical approval was obtained from the ethical review committee of the school of Public Health of the Bahir Dar University. In addition, permission was obtained from the DHS program. The Shape files for the administrative boundaries of Ethiopia were downloaded from the DHS program spatial data repository website [https://www.spatialdata.DHSprogram.com]. The detailed ethical issue is found in the final report of the 2016 EDHS [10].

\section{Results}

\section{Characteristics of study participants and daughters' circumcision}

Nearly three in seven (44\%) women were within the age group of 35-49 years with the mean age of 22.9 years ( $\mathrm{SD} \pm 7.0$ ), and over $90 \%$ of them were married. Over $70 \%$ of mothers of the girls had no education, about one-fifth $(20 \%)$ of them were in the poorest wealth quintile. Nearly four-fifth (82\%) mothers of the daughters had no regular media exposure. Four in five (80\%) mothers of the daughters had a history of circumcision, and about 3 in 10 women (30\%) believed that FGM/C is required by their religion. Twenty-three percent of women believed that the practice should be continued. Nearly one-fourth (24\%) of daughters of the women aged 35-49 years, and more than one-fifth $(21 \%)$ of the daughters of women with no education were circumcised. Overall, $18.6 \%$ of daughters were experienced FGM/C (Table 2).

Most of daughters $(66 \%)$ were circumcised within the ages of 0 to 4 years, whereas, nearly the one-fourth (26\%) of the daughters were circumcised at the ages of 5 to 9 years (Fig. 1).

\section{Community level characteristics}

The majority $(89 \%)$ were study participants were rural residents. Nearly two-fifth (40\%) and one-fourth (25\%) of the study participants were Oromo and Amhara in their Ethnicity, respectively. Nearly one-third (67\%) of women's literacy rate was low, and almost half (50\%) of the communities had low regular media exposure. The proportion of community in the poor wealth quantile was $75 \%$ (Table 3$)$.

\section{Spatial pattern of FGM/C}

The global test for spatial autocorrelation revealed that, a clustered pattern of daughters' FGM/C was observed across the study areas (Moran's I $=0.31, p$-value $<0.001$ ) (Fig. 2).

The most likely primary SaTScan cluster of areas with high rate of FGM/C was detected in Afar, Amhara, Tigray, and Oromia regions $(\mathrm{LLR}=279.0, p<0.01)$. The secondary SaTScan cluster was also detected in Tigray, and Afar regions $(L L R=67.3, p<0.01)$. Somali $(L L R=$ 55.5, $P<0.01$ ), Benishangul Gumuz (LLR =54.9, $\mathrm{P}<$ 0.01 ), Oromia (LLR $=44.9, \mathrm{P}<0.01$ ), and Amhara (LLR = 29.3, $\mathrm{P}<0.01)$ were the regions in which the third, fourth, fifth, and sixth most likely clusters of areas with high rate of daughters' FGM/C were detected, respectively. In addition, the seventh most likely SaTScan cluster was also detected in Somali region $(\mathrm{LLR}=24.5, \mathrm{P}<$ 0.01 ), while the eighth most likely SaTScan cluster $(L L R=22.5, P<0.01)$ in Afar, Oromia and Amhara regions, including Dire Dawa Town (Table 4 and Fig. 3).

In addition, the Getis-Ord $\mathrm{Gi}^{*}$ statistic identified significant hotspots and cold spots of female genital mutilation/cutting which are almost the same as the clusters detected by the Kulldorff's scan statistic (Figs. 3 and 4).

Figure 5 shows the spatial interpolation of FGM/C using inverse distance weighted (IDW) method, which predicts the percentage of FGM/C among girls for the 
Table 2 Characteristics of study participants and the distribution of daughters' FGM/C by background characteristics in Ethiopia, 2016

\begin{tabular}{|c|c|c|c|c|}
\hline \multirow{2}{*}{$\begin{array}{l}\text { Background } \\
\text { Characteristics }\end{array}$} & \multicolumn{2}{|c|}{ Total number of daughters } & \multicolumn{2}{|c|}{ Daughters circumcised } \\
\hline & Frequency & Percent & Frequency & Percent \\
\hline \multicolumn{5}{|c|}{ Maternal age (in years) $($ mean $=22.9, S D \pm 7.04)$} \\
\hline $15-19$ & 84 & 1.2 & 4 & 4.8 \\
\hline $20-24$ & 521 & 7.5 & 59 & 11.3 \\
\hline $25-29$ & 1486 & 21.3 & 196 & 13.2 \\
\hline $30-34$ & 1818 & 26.0 & 305 & 16.8 \\
\hline $35-49$ & 3077 & 44.0 & 739 & 24.0 \\
\hline \multicolumn{5}{|l|}{ Mother's marital status } \\
\hline Married & 6386 & 91.4 & 1185 & 18.6 \\
\hline Divorced & 245 & 3.5 & 61 & 24.9 \\
\hline Widowed & 205 & 2.9 & 37 & 18.0 \\
\hline Others* & 149 & 2.1 & 19 & 12.8 \\
\hline \multicolumn{5}{|l|}{ Religion } \\
\hline Orthodox Christian & 2483 & 35.5 & 655 & 26.4 \\
\hline Muslim & 2677 & 38.3 & 382 & 14.3 \\
\hline Protestant & 1654 & 23.7 & 255 & 15.4 \\
\hline Others** & 171 & 2.5 & 11 & 6.4 \\
\hline \multicolumn{5}{|c|}{ Mother's educational status } \\
\hline No education & 4952 & 70.9 & 1040 & 21.0 \\
\hline Primary & 1642 & 23.5 & 253 & 15.4 \\
\hline Secondary and above & 391 & 5.6 & 9 & 2.3 \\
\hline \multicolumn{5}{|c|}{ Husband/partner's education } \\
\hline No education & 4952 & 70.9 & 1040 & 21 \\
\hline Primary & 1642 & 23.5 & 253 & 15.4 \\
\hline Secondary and above & 391 & 5.6 & 9 & 2.3 \\
\hline \multicolumn{5}{|l|}{ Mother's occupation } \\
\hline Do not work & 3716 & 53.2 & 662 & 17.8 \\
\hline Non-professional & 3174 & 45.4 & 638 & 20.1 \\
\hline Professional & 96 & 1.4 & 2 & 2.1 \\
\hline \multicolumn{5}{|c|}{ Husband/partner's occupation } \\
\hline Do not work & 499 & 7.7 & 111 & 22.2 \\
\hline Non-professional & 5685 & 88 & 1041 & 18.3 \\
\hline Professional & 278 & 4.3 & 44 & 15.8 \\
\hline \multicolumn{5}{|c|}{ Maternal circumcision status } \\
\hline Not circumcised & 1383 & 19.8 & 60 & 4.3 \\
\hline Circumcised & 5602 & 80.2 & 1243 & 22.2 \\
\hline \multicolumn{5}{|l|}{ Wealth Index } \\
\hline Poorest & 1429 & 20.5 & 284 & 19.9 \\
\hline Poorer & 1445 & 20.7 & 276 & 19.1 \\
\hline Middle & 1477 & 21.1 & 284 & 19.2 \\
\hline Richer & 1541 & 22.1 & 328 & 21.3 \\
\hline Richest & 1093 & 15.6 & 130 & 11.9 \\
\hline
\end{tabular}

Number of living children 
Table 2 Characteristics of study participants and the distribution of daughters' FGM/C by background characteristics in Ethiopia, 2016 (Continued)

\begin{tabular}{|c|c|c|c|c|}
\hline \multirow{2}{*}{$\begin{array}{l}\text { Background } \\
\text { Characteristics }\end{array}$} & \multicolumn{2}{|c|}{ Total number of daughters } & \multicolumn{2}{|c|}{ Daughters circumcised } \\
\hline & Frequency & Percent & Frequency & Percent \\
\hline $1-2$ & 1152 & 16.5 & 132 & 11.5 \\
\hline $3-4$ & 2094 & 30 & 369 & 17.6 \\
\hline $5-6$ & 2080 & 29.8 & 463 & 22.3 \\
\hline $7+$ & 1659 & 23.8 & 338 & 20.4 \\
\hline \multicolumn{5}{|l|}{ Sex of household head } \\
\hline Male & 5765 & 82.5 & 1036 & 18 \\
\hline Female & 1220 & 17.5 & 267 & 21.9 \\
\hline \multicolumn{5}{|c|}{ Mother's relation to the head of the household } \\
\hline Wife & 5535 & 79.2 & 1014 & 18.3 \\
\hline Head & 1045 & 15 & 236 & 22.6 \\
\hline Daughter or daughter-in-law & 307 & 4.4 & 35 & 11.4 \\
\hline Other ${ }^{* * *}$ & 98 & 1.4 & 17 & 17.3 \\
\hline \multicolumn{5}{|l|}{ Had regular media exposure } \\
\hline No & 5706 & 81.7 & 1202 & 21.1 \\
\hline Yes & 1279 & 18.3 & 101 & 7.9 \\
\hline \multicolumn{5}{|c|}{ Perceived religious believes to FGM/C } \\
\hline Not required & 4531 & 64.9 & 645 & 14.2 \\
\hline Required & 2085 & 29.8 & 580 & 27.8 \\
\hline Do not know/ no religion & 369 & 5.3 & 77 & 20.9 \\
\hline \multicolumn{5}{|c|}{ Opinions of women towards the practice of FGM/C } \\
\hline Stop & 5058 & 72.4 & 692 & 13.7 \\
\hline Continue & 1593 & 22.8 & 557 & 35 \\
\hline Depends/ do not know & 334 & 4.8 & 53 & 15.9 \\
\hline \multicolumn{5}{|c|}{ Ever heard of female circumcision } \\
\hline No & 88 & 1.3 & 4 & 4.5 \\
\hline Yes & 6897 & 98.7 & 1298 & 18.8 \\
\hline Total & 6985 & 100 & 1302 & 18.6 \\
\hline
\end{tabular}

*Catholic, traditional, and other; ${ }^{* *}$ never in union, separated/no longer living together; ${ }^{* *}$ Daughter; granddaughter; mother, sister, other relative, adopted/foster child and not related

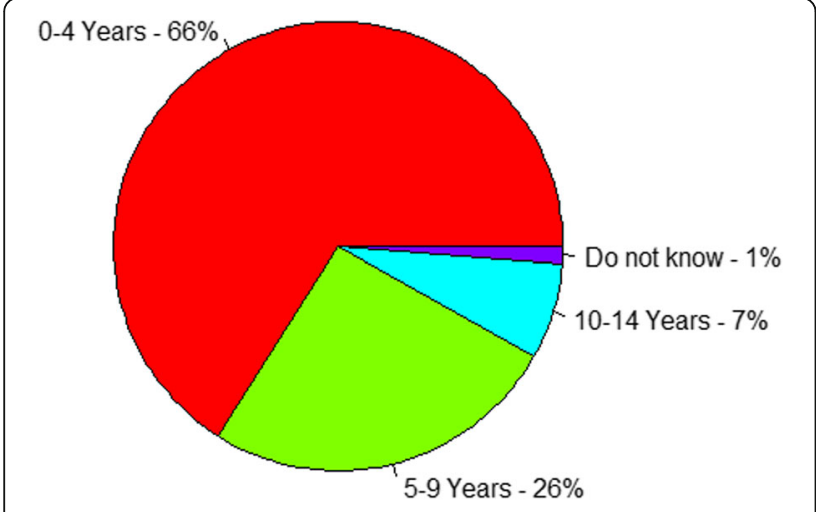

Fig. 1 Distribution of girls by age at circumcision, EDHS 2016 unmeasured location across the country from the limited number of sample data points. More than $75 \%$ of the girls were circumcised in most part of Afar region (Fig. 5).

\section{Multilevel analysis}

In the multilevel regression analysis where both individual and community level factors were included, the final best fit model (model IV) revealed that maternal age, maternal education, households wealth index, maternal circumcision status, number of living children, regular exposure to media, perceived religious believes to FGM/ $\mathrm{C}$, women's opinion towards the practice of $\mathrm{FGM} / \mathrm{C}$ were statistical significant individual-level factors associated with the daughters' FGM/C. In addition, place of residence, geographical region, ethnicity, and community 
Table 3 Community level characteristics and distribution of daughters' circumcision by community level characteristics in Ethiopia, 2016

\begin{tabular}{|c|c|c|c|c|}
\hline \multirow{2}{*}{$\begin{array}{l}\text { Background } \\
\text { characteristics }\end{array}$} & \multicolumn{2}{|c|}{ Total number of daughters } & \multicolumn{2}{|c|}{ Daughters circumcised } \\
\hline & Frequency & Percent & Frequency & Percent \\
\hline \multicolumn{5}{|l|}{ Residence } \\
\hline Urban & 794 & 11.4 & 70 & 8.8 \\
\hline Rural & 6191 & 88.6 & 1233 & 19.9 \\
\hline \multicolumn{5}{|l|}{ Region } \\
\hline Tigray & 390 & 5.6 & 52 & 13.3 \\
\hline Afar & 65 & 0.9 & 51 & 78.5 \\
\hline Amhara & 1473 & 21.1 & 581 & 39.4 \\
\hline Oromia & 3019 & 43.2 & 269 & 8.9 \\
\hline Somali & 238 & 3.4 & 76 & 31.9 \\
\hline Benishangul Gumuz & 72 & 1.0 & 17 & 23.3 \\
\hline SNNPR & 1532 & 21.9 & 247 & 16.1 \\
\hline Gambella & 10 & 0.1 & 1 & 10.0 \\
\hline Harari & 17 & 0.2 & 2 & 11.8 \\
\hline Addis Ababa & 140 & 2.0 & 2 & 1.4 \\
\hline Dire Dawa & 29 & 0.4 & 4 & 13.8 \\
\hline \multicolumn{5}{|l|}{ Ethnicity } \\
\hline Affar & 60 & 0.9 & 49 & 81.7 \\
\hline Somalie & 227 & 3.2 & 71 & 31.3 \\
\hline Amhara & 1749 & 25.0 & 547 & 31.3 \\
\hline Oromo & 2812 & 40.3 & 302 & 10.7 \\
\hline Tigrie & 394 & 5.6 & 51 & 12.9 \\
\hline Sidama & 340 & 4.9 & 49 & 14.4 \\
\hline Wolaita & 228 & 3.3 & 77 & 33.8 \\
\hline Guragie & 115 & 1.6 & 16 & 13.9 \\
\hline Siltie & 109 & 1.6 & 13 & 11.9 \\
\hline Dawuro & 62 & 0.9 & 27 & 42.9 \\
\hline Kembata & 61 & 0.9 & 12 & 19.7 \\
\hline Berta & 25 & 0.4 & 12 & 48.0 \\
\hline Agew Awi & 11 & 0.2 & 5 & 45.5 \\
\hline Hadiya & 218 & 3.1 & 42 & 19.4 \\
\hline Others* & 574 & 8.2 & 29 & 5.0 \\
\hline \multicolumn{5}{|c|}{ Women's literacy rate of the community } \\
\hline Low & 4746 & 67.9 & 880 & 18.6 \\
\hline High & 2239 & 32.1 & 422 & 18.7 \\
\hline \multicolumn{5}{|c|}{ Proportion of community with regular media exposure } \\
\hline Low & 3465 & 49.6 & 791 & 22.8 \\
\hline High & 3520 & 50.4 & 511 & 14.5 \\
\hline \multicolumn{5}{|c|}{ Proportion of community in the poor wealth quantile } \\
\hline Low & 1735 & 24.8 & 359 & 20.6 \\
\hline High & 5250 & 75.2 & 943 & 17.9 \\
\hline Total & 6985 & 100.0 & 1302 & 18.6 \\
\hline
\end{tabular}

*Nuwer, Kefficho, Gumuz, Gamo, Anyiwak, Gedeoi, Derashe, Dizi, Agew Hamyra, Goffa, Argoba, Ari, Harari, Basketo, Konta, Komo, Koyego, Mao, Bench, Shekecho, Sheko, Shinasha, Burji, Bena, Yem, etc. 


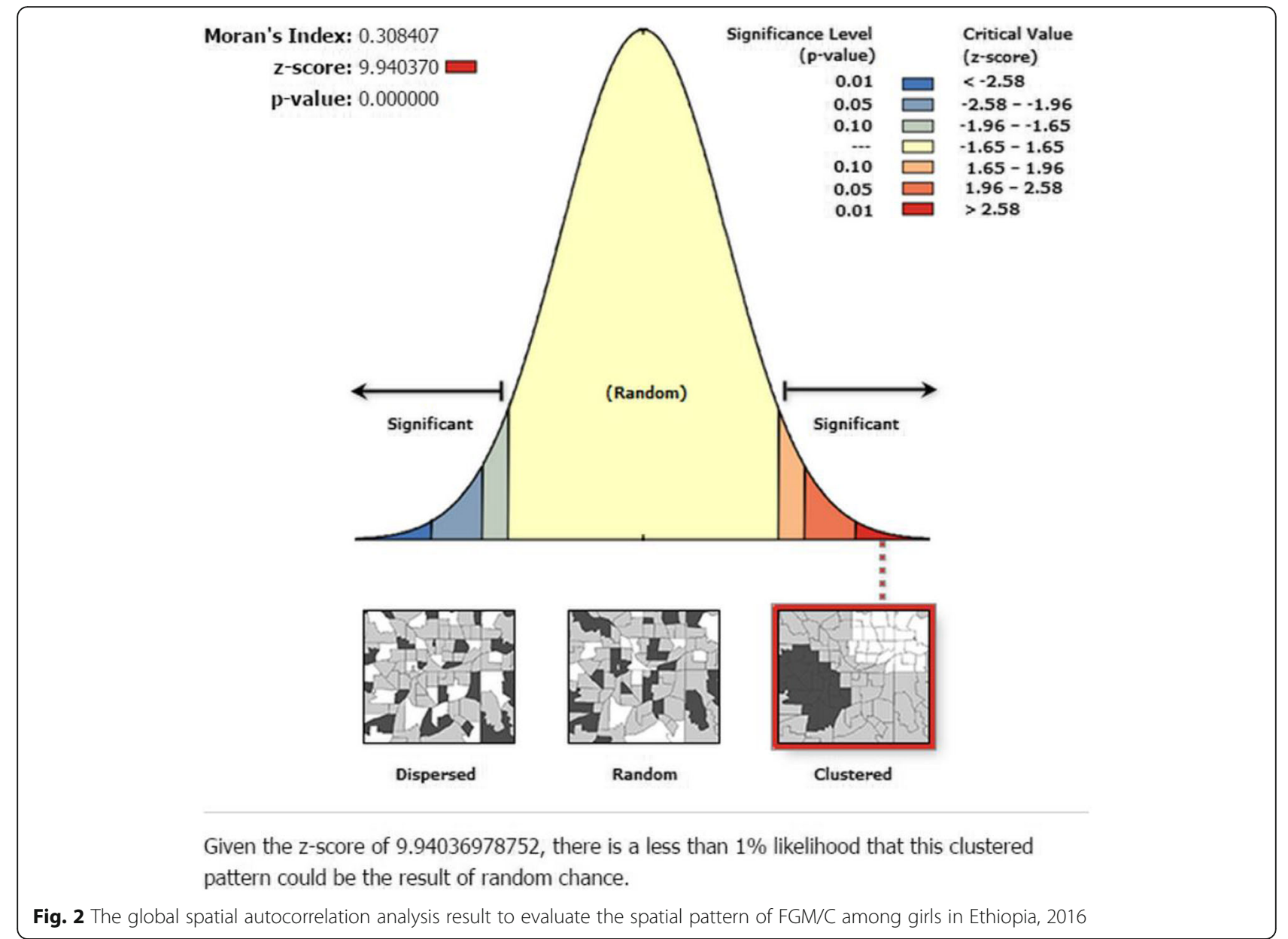

with regular media exposure were the community level factors associated with the practice of FGM/C (Table 5).

Individual level factors: The daughters of women aged $35-49$ years were 3.5 times $(\mathrm{AOR}=3.51$; 95\% CI: $1.45-$ 8.5) more likely to be circumcised than the daughters of women aged 15-19 years. Daughters whose maternal educational status was secondary and above were $57 \%$ less likely to experience genital mutilation $(\mathrm{AOR}=0.43$; $95 \%$ CI: $0.22-0.84)$ compared to those daughters with no maternal education. The odds of daughters' circumcision were decreased by $57 \%(\mathrm{AOR}=0.43 ; 95 \% \mathrm{CI}: 0.22-0.84$ ) in daughters with secondary and higher maternal education compared to daughters whose mothers had no education. The daughters of circumcised women were seven times more likely ( $\mathrm{AOR}=7.49 ; 95 \% \mathrm{CI}: 4.84-11.59)$ to be circumcised as compared with their counter parts.

The odds of daughters circumcision in the households with richer and richest wealth quantile were 0.46 times (AOR $=0.54 ; 95 \% \mathrm{CI}: 0.30-0.82$ ), and 0.7 times $(\mathrm{AOR}=$ 0.70; 95\% CI 0.46-0.92) higher than those daughters

Table 4 Spatial clusters female genital mutilation/cutting among girls in Ethiopia, 2016

\begin{tabular}{|c|c|c|c|c|c|c|c|}
\hline Cluster & Regions & Radius (km) & Obs.* & Exp.** & RR & LLR & $p$-value \\
\hline 1 & Amhara, Afar, Tigray, and Oromia regions & 243.6 & 682 & 279.7 & 3.60 & 279.0 & 0.001 \\
\hline 2 & Tigray and Afar regions & 60.1 & 95 & 22.6 & 4.61 & 67.3 & 0.001 \\
\hline 3 & Somali region & 437.5 & 200 & 92.9 & 2.57 & 55.5 & 0.001 \\
\hline 4 & Benishangul Gumuz region & 57.1 & 88 & 23.8 & 4.21 & 54.9 & 0.001 \\
\hline 5 & Oromia and SNNPR regions & 124.9 & 140 & 61.5 & 2.83 & 44.9 & 0.001 \\
\hline 6 & Amhara region & 80.8 & 28 & 4.4 & 6.91 & 29.3 & 0.001 \\
\hline 7 & Somali region & 259.5 & 29 & 5.8 & 5.46 & 24.5 & 0.001 \\
\hline 8 & Afar, Oromia, and Amhara regions including Dire Dawa Town & 230.7 & 84 & 40.4 & 2.59 & 22.5 & 0.001 \\
\hline
\end{tabular}

RR: Relative risk; LLR: Log likelihood ratio; ${ }^{*}$ Number of observed cases in a cluster; ${ }^{* *}$ Number of expected cases in a cluster 


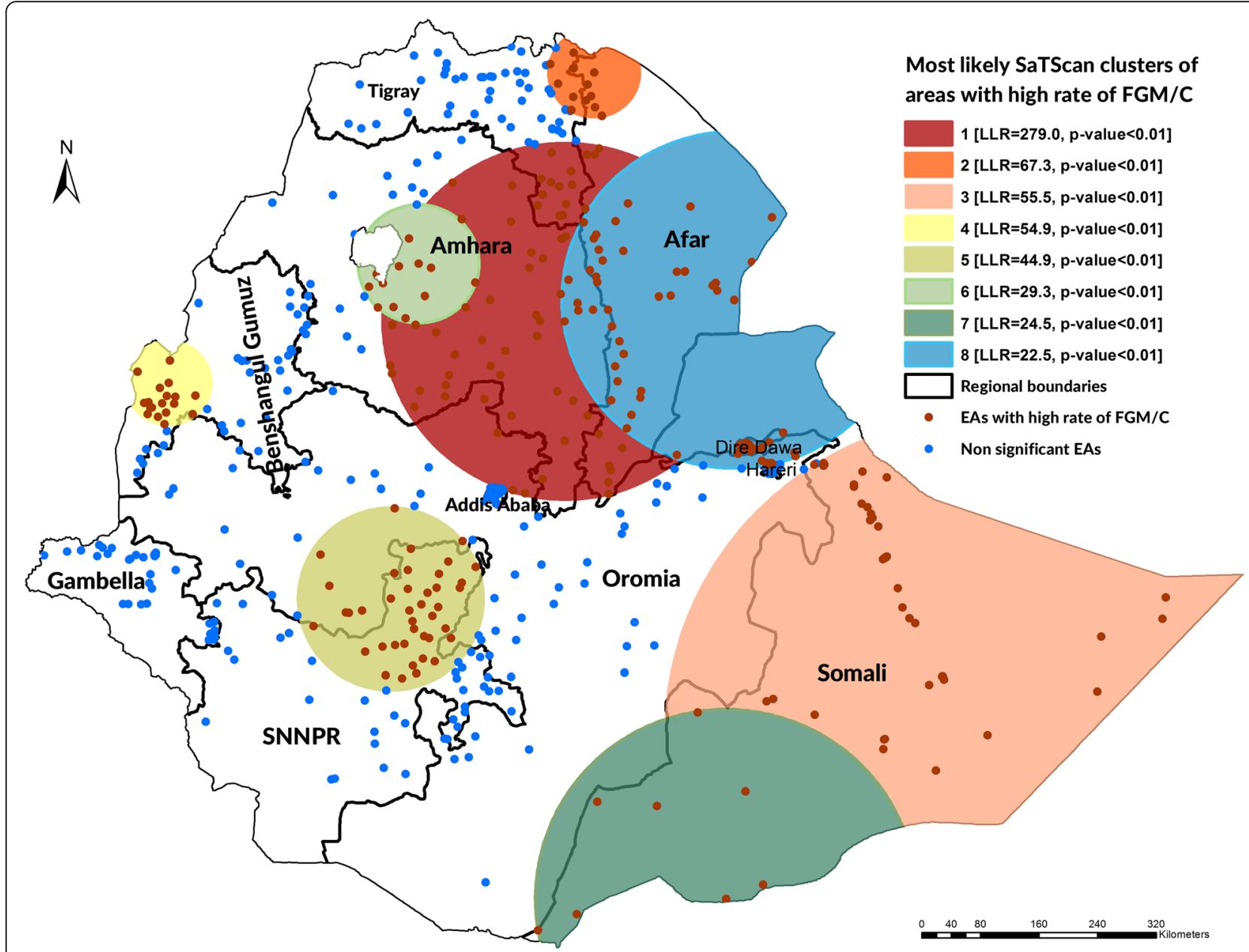

Fig. 3 Spatial clustering of areas with high rate of daughters' FGM/C in Ethiopia, 2016

from the households with the poorest wealth quantile, respectively. The odds of circumcision among daughters from the households having 5 to 6 and seven or more number of living children were 1.89 times $(\mathrm{AOR}=1.89$, 95\% CI 1.37-2.60), and 1.62 times ( $\mathrm{AOR}=1.62 ; 95 \% \mathrm{CI}$ 1.13-2.32) higher than those daughters from the households having two or less number of living children, respectively. The daughters of women who believe that $\mathrm{FGM} / \mathrm{C}$ is required by their religion were more likely $(\mathrm{AOR}=1.42,95 \% \mathrm{CI}: 1.17-1.83)$ to have circumcision than their counter parts. The odds of circumcision among daughters from women who support the continuation of FGM/C practice was 2.5 times more likely $(\mathrm{AOR}=2.50,95 \% \mathrm{CI}: 1.99-3.14)$ than the daughters from the women who did not support the continuation of the practice. Women's regular media exposure decreases the odds of circumcision in their daughters by $49 \%(\mathrm{AOR}=0.51 ; 95 \% \mathrm{CI}: 0.35-0.77)$ compared to their counter parts (Table 5).

Community level factors: The odds of daughters' FGM/C were increased by $51 \%$ (AOR $=2.51$; $95 \%$ CI: $1.46-$
4.33) among daughters living in rural areas compared to the daughters living in urban areas. Compared with Afar region, the odds of daughters' FGM/C were lower in Tigray (AOR $=0.07$; 95\% CI: 0.01-0.36), Oromia (AOR $=0.05$; 95\% CI: 0.02-0.13), Somali (AOR $=0.24 ; 95 \%$ CI: 0.07-0.77), Benishangul Gumuz (AOR $=0.13$; 95\%CI: 0.05-0.37), SNNPR (AOR $=0.09 ; 95 \%$ CI: 0.03-0.27), Gambella (AOR = 0.13; 95\%CI: 0.04-0.44) regions including Harari, Addis Ababa, and Dire Dawa towns. In addition, the practice of FGM/C is less likely in ethnicities of Somali, Amhara, Oromo, Sidama Guragie, and Siltie compared with Afar Ethnicity. The higher proportion of community with regular media exposure decreases the odds of circumcision in their daughters by $30 \%(\mathrm{AOR}=0.70 ; 95 \% \mathrm{CI}: 0.48-0.91)$ compared to their counterparts (Table 5).

\section{Measures of variation (random-effects) and model fit statistic}

As the multilevel logistic regression analysis results depicted in Table 6, the null model revealed statistically significant variation in FGM/C among communities $[\tau=5.86, p<$ 


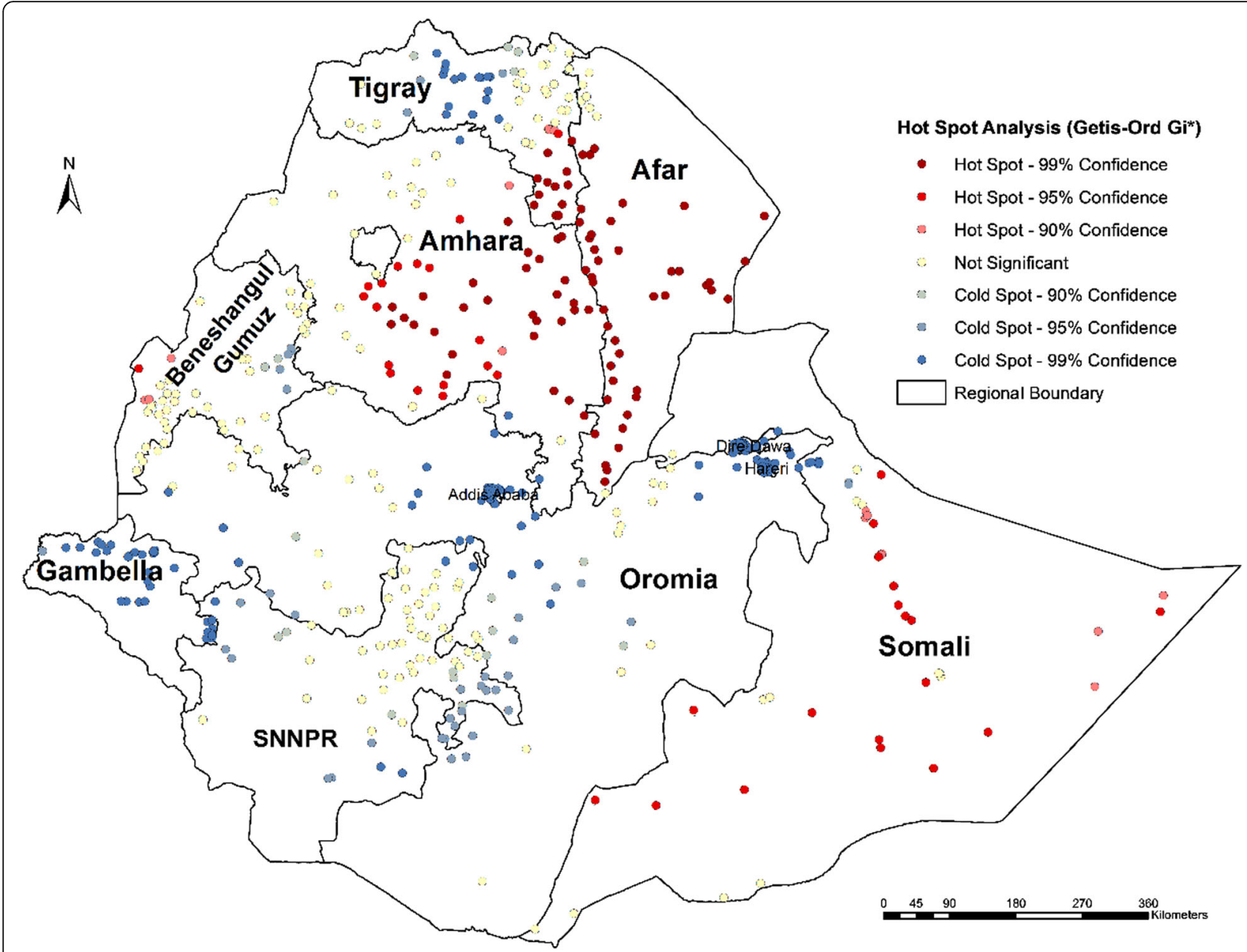

Fig. 4 FGM/C hotspots in Ethiopia (Getis-Ord-Gi* statistic), EDHS 2016

0.001], and the odds of FGM/C in daughters was attributed to community-level factors (ICC $=64 \%$ ). After incorporating the individual level characteristics to the null model, the variation in the odds of $\mathrm{FGM} / \mathrm{C}$ among the communities remained significant $[\tau=3.19, \mathrm{p}<0.001]$ with the ICC of $49 \%$. As compared to the variance in model 2 , incorporating community-level characteristics to the null model decreased the variance in FGM/C among the communities $[\tau=1.58$, $\mathrm{p}<0.001$ ], and also the ICC lowered to $32.4 \%$.

The final best fit model (model 4) which incorporated both the individual and community level characteristics revealed statistically significant variability in the odds of FGM/C among the communities $[\tau=0.99, p<0.001]$ with the ICC of $23 \%$. The PCV comparing the null model (Model 1) with the model containing both individual and community characteristics (Model 4) was 0.831 , and it indicated that about $83 \%$ of the variance in the odds of FGM/C was attributed to both individual and community-level characteristics.

In this study, the MOR was 9.98 in the null model (model 1), 5.45 in model 2, 3.30 in model 3, and 2.57 in model 4. Hence, MOR of 9.98 in the null model indicated the presence of heterogeneity across communities, and incorporating both individual and community level factors to the null model could reduce the unexplained heterogeneity to the MOR of 2.57 (Table 6).

\section{Discussions}

In this study, the overall prevalence of FGM/C among girls was found to be $18.6 \%$, which indicates declining as compared to the national prevalence (24\%) reported in the 2005 EDHS [9]. The finding is supported by other evidences which revealed that Ethiopia has made significant progress in the last two decades in reducing girls' vulnerability to $\mathrm{FGM} / \mathrm{C}[9,10,13]$. It is also low as compared to the most recent DHS reports of other African countries such as Mali, 73\%, and Guinea, 39\% [33]. Despite this progress, many girls are still at risk with geographical variation [13]. On the other hand, the practice is high as compared with similar survey reports of Egypt, $12 \%$ [34], Kenya, 3\% [35], chad, 10\% [33, 36]\%, Tanzania, $0.4 \%[37]$. 


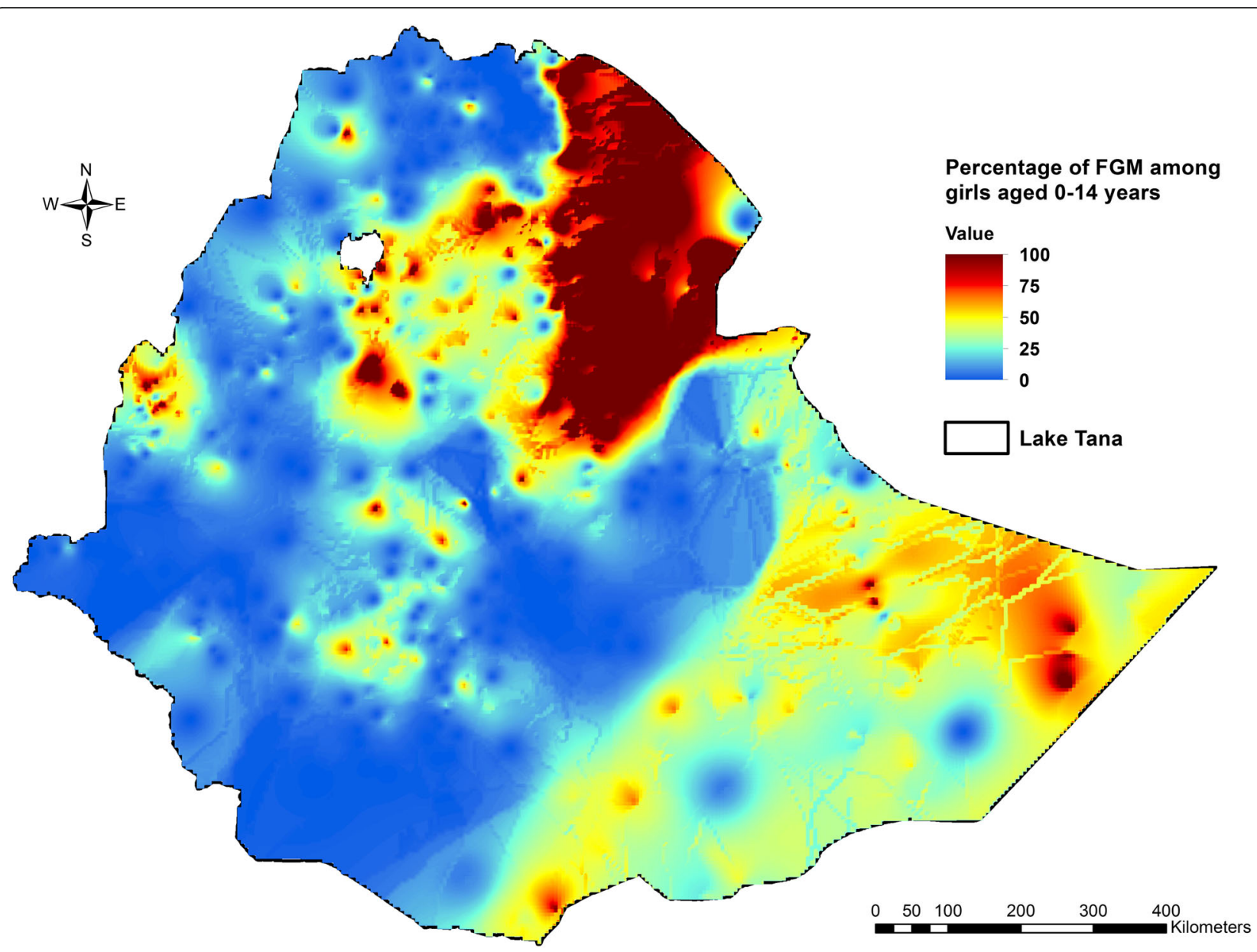

Fig. 5 A spatial interpolation of FGM/C among girls in Ethiopia from the sample data points using an inverse distance weighted (IDW) technique.

The global test for spatial autocorrelation indicated the presence of clustering in FGM/C across the study areas without specifying the spatial location (Moran's $\mathrm{I}=0.31, p$-value $<0.01)$. This could indicate that the practice of FGM/C is clustered across the communities in the country, and suggested an extended local test, a focused test which used to detect local clusters of areas with high rate of FGM/C. The results of other studies in and outside Ethiopia also supported this finding of spatial clustering in FGM/C practice $[24,38]$.

The Kulldorff's spatial scan statistic detected FGM/C 'hotspots' among girls in Ethiopia. Moreover, the results of the Getis-Ord $\mathrm{Gi}^{*}$ statistic supported and confirmed the results of the findings of the Kulldorff's purely spatial analysis.

In this study, northeastern parts of the country, particularly in Afar, Amhara, Tigray and Oromia regions, were detected as FGM/C hotspots. This may be due to the fact that the neighborhood areas of the regions may share common characteristics in relation to traditional practices. In addition, FGM/C hotspots were detected
Somali, Benishangul Gumuz, and SNNPR regions including Dire Dawa Town. This finding can indicate that the communities located in the Northern, Northeastern and Eastern parts of the country are FGM/C 'hotspots' and are areas in need of urgent attention. This local clustering of $\mathrm{FGM} / \mathrm{C}$ can also indicate that daughters who lived in the FGM/C hotspot areas had a high probability of experiencing circumcision compared with those who lived outside the identified clusters. This may be due to differences in community background characteristics such as Ethnicity, religion, community perception to $\mathrm{FGM} / \mathrm{C}$, and this identification of clusters with high FGM/C practice can lead to targeted interventions.

The multilevel regression analysis confirmed that the variation in daughters' $\mathrm{FGM} / \mathrm{C}$ in Ethiopia was attributed to both individual and community level factors which accounted for $83 \%$ of the variation.

Like other studies [24,39], this study identified maternal age, household wealth index, maternal education, number of living children, perceived religious believes to FGM/C, opinions of women towards the practice of 
Table 5 Individual and community level factors affecting daughters' FGM/C in Ethiopia, 2016 (a multilevel logistic regression analysis)

\begin{tabular}{|c|c|c|c|}
\hline Variables & Model II AOR (95\%CI) & Model IIIAOR (95\%CI) & Model IVAOR $(95 \% \mathrm{Cl})$ \\
\hline \multicolumn{4}{|l|}{ Individual level factors } \\
\hline \multicolumn{4}{|l|}{ Maternal age (in years) } \\
\hline $15-19$ & 1.00 & - & 1.00 \\
\hline $20-34$ & $1.19(0.53-2.7)$ & - & $1.61(0.68-3.8)$ \\
\hline $35-49$ & $2.31(1.00-5.36)$ & - & $3.51(1.45-8.5)^{*}$ \\
\hline \multicolumn{4}{|c|}{ Religion } \\
\hline Orthodox Christian & 1.00 & - & 1.00 \\
\hline Muslim & $1.52(1.03-2.24)$ & - & $1.05(0.7-1.58)$ \\
\hline Protestant & $0.67(0.42-1.07)$ & - & $0.89(0.54-1.47)$ \\
\hline Others* & $0.23(0.05-0.94)$ & - & $0.29(0.08-1.03)$ \\
\hline \multicolumn{4}{|l|}{ Mother's educational status } \\
\hline No education & 1.00 & - & 1.00 \\
\hline Primary & $0.96(0.76-1.22)$ & - & $1.06(0.84-1.34)$ \\
\hline Secondary and above & $0.29(0.15-0.58)$ & - & $0.43(0.22-0.84)^{*}$ \\
\hline \multicolumn{4}{|l|}{ Mother's occupation } \\
\hline Do not work & 1.00 & - & 1.00 \\
\hline Non-professional & $1.04(0.85-1.27)$ & - & $1.08(0.88-1.31)$ \\
\hline Professional & $0.44(0.13-1.46)$ & - & $0.51(0.16-1.66)$ \\
\hline \multicolumn{4}{|l|}{ Maternal circumcision status } \\
\hline Not circumcised & 1.00 & - & 1.00 \\
\hline Circumcised & $7.37(4.69-11.59)$ & - & $7.49(4.84-11.59)^{*}$ \\
\hline \multicolumn{4}{|l|}{ Wealth Index } \\
\hline Poorest & 1.00 & - & 1.00 \\
\hline Poorer & $0.91(0.68-1.23)$ & - & $1.25(0.93-1.67)$ \\
\hline Middle & $0.89(0.66-1.22)$ & - & $1.30(0.96-1.76)$ \\
\hline Richer & $0.30(0.10-0.51)$ & - & $0.54(0.30-0.82)^{*}$ \\
\hline Richest & $0.65(0.43-0.89)$ & - & $0.70(0.46-0.92)^{*}$ \\
\hline \multicolumn{4}{|l|}{ Number of living children } \\
\hline $1-2$ & 1.00 & - & 1.00 \\
\hline $3-4$ & $1.28(0.94-1.74)$ & - & $1.27(0.93-1.72)$ \\
\hline $5-6$ & $2.03(1.47-2.8)$ & - & $1.89(1.37-2.60)^{*}$ \\
\hline $7+$ & $1.82(1.28-2.61)$ & - & $1.62(1.13-2.32)^{*}$ \\
\hline \multicolumn{4}{|l|}{ Sex of household head } \\
\hline Male & 1.00 & - & 1.00 \\
\hline Female & $1.38(0.62-3.08)$ & - & $1.41(0.62-3.22)$ \\
\hline \multicolumn{4}{|c|}{ Mother's relation to the head of the household } \\
\hline Wife & 1.00 & - & 1.00 \\
\hline Head & $1.06(0.46-2.44)$ & - & $1.02(0.44-2.4)$ \\
\hline Daughter or daughter-in-law & $0.88(0.44-1.76)$ & - & $0.81(0.4-1.67)$ \\
\hline Other & $0.88(0.35-2.19)$ & - & $0.71(0.28-1.8)$ \\
\hline \multicolumn{4}{|l|}{ Had regular media exposure } \\
\hline No & 1.00 & - & 1.00 \\
\hline Yes & $0.56(0.39-0.80)$ & - & $0.51(0.35-0.77)^{*}$ \\
\hline
\end{tabular}


Table 5 Individual and community level factors affecting daughters' FGM/C in Ethiopia, 2016 (a multilevel logistic regression analysis) (Continued)

\begin{tabular}{|c|c|c|c|}
\hline Variables & Model II AOR (95\%Cl) & Model IIIAOR $(95 \% \mathrm{Cl})$ & Model IVAOR $(95 \% \mathrm{Cl})$ \\
\hline \multicolumn{4}{|c|}{ Perceived religious believes to FGM/C } \\
\hline Not required & 1.00 & - & 1.00 \\
\hline Required & $1.57(1.25-1.97)$ & - & $1.47(1.17-1.83)^{*}$ \\
\hline Do not know/ no religion & $1.17(0.74-1.84)$ & - & $1.16(0.75-1.80)$ \\
\hline \multicolumn{4}{|c|}{ Opinions of women towards the practice of FGM/C } \\
\hline Stop & 1.00 & - & 1.00 \\
\hline Continue & $2.68(2.12-3.38)$ & - & $2.50(1.99-3.14)^{*}$ \\
\hline Depends/ do not know & $1.46(0.88-2.42)$ & - & $1.53(0.93-2.51)$ \\
\hline \multicolumn{4}{|c|}{ Ever heard of female circumcision } \\
\hline No & 1.00 & - & 1.00 \\
\hline Yes & $1.52(0.35-6.6)$ & - & $1.67(0.38-7.42)$ \\
\hline \multicolumn{4}{|l|}{ Community level factors } \\
\hline \multicolumn{4}{|l|}{ Residence } \\
\hline Urban & - & 1.00 & 1.00 \\
\hline Rural & - & $3.29(1.87-5.78)$ & $2.51(1.46-4.33)^{*}$ \\
\hline \multicolumn{4}{|l|}{ Region } \\
\hline Afar & - & 1.00 & 1.00 \\
\hline Tigray & - & $0.04(0.01-0.19)$ & $0.07(0.01-0.36)^{*}$ \\
\hline Amhara & - & $0.60(0.23-1.58)$ & $0.56(0.21-1.49)$ \\
\hline Oromia & - & $0.05(0.02-0.13)$ & $0.05(0.02-0.13)^{*}$ \\
\hline Somali & - & $0.35(0.10-1.17)$ & $0.24(0.07-0.77)^{*}$ \\
\hline Benishangul Gumuz & - & $0.10(0.03-0.28)$ & $0.13(0.05-0.37)^{*}$ \\
\hline SNNPR & - & $0.09(0.03-0.26)$ & $0.09(0.03-0.27)^{*}$ \\
\hline Gambella & - & $0.06(0.02-0.21)$ & $0.13(0.04-0.44)^{*}$ \\
\hline Harari & - & $0.07(0.02-0.21)$ & $0.06(0.02-0.16)^{*}$ \\
\hline Addis Ababa & - & $0.03(0.01-0.10)$ & $0.05(0.01-0.19)^{*}$ \\
\hline Dire Dawa & - & $0.16(0.05-0.45)$ & $0.11(0.04-0.30)^{*}$ \\
\hline \multicolumn{4}{|l|}{ Ethnicity } \\
\hline Afar & - & 1.00 & 1.00 \\
\hline Somalie & - & $0.15(0.05-0.49)$ & $0.18(0.05-0.56)^{*}$ \\
\hline Amhara & - & $0.08(0.03-0.19)$ & $0.18(0.07-0.45)^{*}$ \\
\hline Oromo & - & $0.09(0.04-0.23)$ & $0.15(0.06-0.38)^{*}$ \\
\hline Tigrie & - & $0.16(0.04-0.65)$ & $0.43(0.09-2.16)$ \\
\hline Sidama & - & $0.09(0.03-0.34)$ & $0.16(0.04-0.61)^{*}$ \\
\hline Wolaita & - & $0.40(0.13-1.24)$ & $0.70(0.21-2.29)$ \\
\hline Guragie & - & $0.14(0.04-0.44)$ & $0.19(0.06-0.62)^{*}$ \\
\hline Siltie & - & $0.06(0.01-0.30)$ & $0.11(0.02-0.57)^{*}$ \\
\hline Dawuro & - & $0.81(0.10-6.84)$ & $1.38(0.21-9.24)$ \\
\hline Kembata & - & $0.30(0.07-1.35)$ & $0.54(0.12-2.54)$ \\
\hline Berta & - & $0.67(0.19-2.36)$ & $0.77(0.23-2.61)$ \\
\hline Agew Awi & - & $0.03(0.00-0.26)$ & $0.14(0.02-1.27)$ \\
\hline Hadiya & - & $0.16(0.05-0.54)$ & $0.29(0.08-1.01)$ \\
\hline Others & - & $0.04(0.02-0.12)$ & $0.11(0.04-0.31)^{*}$ \\
\hline
\end{tabular}


Table 5 Individual and community level factors affecting daughters' FGM/C in Ethiopia, 2016 (a multilevel logistic regression analysis) (Continued)

\begin{tabular}{|c|c|c|c|}
\hline Variables & Model II AOR $(95 \% \mathrm{Cl})$ & Model IIIAOR (95\%CI) & Model IVAOR $(95 \% \mathrm{Cl})$ \\
\hline \multicolumn{4}{|c|}{ Women's literacy rate of the community } \\
\hline Low & - & 1.00 & 1.00 \\
\hline High & - & $0.84(0.55-1.28)$ & $0.88(0.60-1.28)$ \\
\hline \multicolumn{4}{|c|}{ Proportion of community with regular media exposure } \\
\hline Low & - & 1.00 & 1.00 \\
\hline High & - & $0.67(0.42-0.88)$ & $0.70(0.48-0.91)^{*}$ \\
\hline \multicolumn{4}{|c|}{ Proportion of community in the poor wealth quantile } \\
\hline Low & - & 1.00 & 1.00 \\
\hline High & - & $0.71(0.44-1.14)$ & $0.79(0.51-1.21)$ \\
\hline
\end{tabular}

*p-value $<0.05$

FGM/C, and regular media exposure as individual level factors associated with the practice of FGM/C.

In this study, older maternal age was found to be a factor to increase the risk of FGM/C among their daughters. This could be justified by lower awareness of FGM/ $\mathrm{C}$ impacts in older age women, and older women may be more likely to conform to traditional practices, including FGM/C.

The results of this study showed that the daughters of women with secondary or higher educational status had lower odds of experiencing FGM/C compared to the those who had no education, and it is supported by other studies conducted in and out of Ethiopia [24, 39]. This less risk of daughters for FGM/C in educated mothers could be justified as women who had completed secondary school or above are more likely to be aware of the FGM/C risks; they may have better opportunity in information communication, and lower tendency to practice $\mathrm{FGM} / \mathrm{C}$ on their daughters. In addition, educated women are more likely to evaluate their own beliefs and values related to the practice [1]. Moreover, education empowers women not only to get new knowledge but also improve the sharing of experiences [1].

Compared to the daughters of uncircumcised women, the daughters of circumcised women are at higher risk of $\mathrm{FGM} / \mathrm{C}$, and this finding is consistent with another study finding in Kenya [39]. This may be due to the higher tendency of circumcised women to support the continuation of FGM/C than the uncircumcised women. This finding may suggest that communities who are currently practicing FGM/C among the daughters may also be at considerable risk of continuing the $\mathrm{FGM} / \mathrm{C}$ practice persistently in the future.

Like what has been documented elsewhere [24, 4042], this finding of this study revealed that the risk of FGM/C among girls is lower in the households with better wealth status compared to their counterparts. The possible reason for this could be due to the decision making power of women in relation to their wealth. As evidences revealed, improved economic status can enhance the role of women in decision making not to support the continuation of FGM/C practice $[38,43,44]$.

Table 6 Results from random intercept model (measures of variation) for daughters' circumcision at cluster level by multilevel logistic regression analysis

\begin{tabular}{|c|c|c|c|c|}
\hline Measures of variation & Model $1^{a}$ & Model $2^{b}$ & Model $3^{c}$ & Model $4^{d}$ \\
\hline \multicolumn{5}{|l|}{ Community level } \\
\hline Variance (SE) & $5.863(0.129)^{*}$ & $3.189(0.103)^{*}$ & $1.577(0.084)^{*}$ & $0.988(0.076)^{*}$ \\
\hline Explained variation (PCV) & Reference & 45.6 & 73.1 & 83.1 \\
\hline ICC (\%) & 64.1 & 49.2 & 32.4 & 23.1 \\
\hline $\mathrm{MOR}^{\mathrm{e}}$ & 9.98 & 5.45 & 3.30 & 2.57 \\
\hline \multicolumn{5}{|l|}{ Model fit statistics } \\
\hline DIC (-2log likelihood) & 5197 & 4626 & 4736 & 4272 \\
\hline
\end{tabular}

* $p$-value $<0.001$

SE: Standard Error; PCV: Proportional Change in Variance; ICC: Intraclass Correlation Coefficient; MOR: Median Odds Ratio; DIC: Deviance Information Criterion. ${ }^{\mathrm{a}}$ Model 1 is the null model, a baseline model without any predictor variable ${ }^{\mathrm{b}}$ Model 2 is the model fitted with individual level factors ${ }^{\mathrm{c}}$ Model 3 is the model fitted with community level factors ${ }^{\mathrm{d}}$ Model 4 is the final model fitted with both individual and community level factors

e Increased risk (in median) that one would have if moving to a neighborhood/cluster with a higher risk 
In many communities, the practice of $\mathrm{FGM} / \mathrm{C}$ is believed to be a deeply rooted traditional practice, which is attributed to the cultures and religion [1, 2, 7, 39, 45]. However, the finding of this study could not show statistically significant association between religion and the practice of FGM/C. This finding also contradicted with the findings of other studies in Ethiopia, and Kenya [24, 39], where a statistical association between religion and the practice $\mathrm{FGM} / \mathrm{C}$ was reported. Other evidences indicated that the practice of $\mathrm{FGM} / \mathrm{C}$ is more likely in Muslim communities [39, 46]. However, not only Muslim communities practice $\mathrm{FGM} / \mathrm{C}$, but also many other non-Muslim ones do [39]. This can suggest that the association between the practice of FGM/C and religion varies widely across countries, regions and communities. On the other hand, this study revealed that the daughters of women who believed as FGM/C is required by religion were more likely to be circumcised as compared to their counter parts. The daughters were less likely to be circumcised if their mothers had regular mass media exposure, which is supported by the findings of another studies [24, 44].

Among the community level characteristics incorporated in this study, place of residence, geographical region, ethnicity and proportion of community with regular media exposure were identified as factors affecting the practice of FGM/C. In contrast to a study findings in Kenya [38], this study revealed that the daughters in the rural areas are at higher risk of FGM/C than the daughters in urban areas. This could be justified in that communities in rural area may be more likely to have limited cultural diversity, and in communities where continuation of FGM/C is supported, it could be challenging to escape conventions or norms that hold the practice in place [39]. On the other hand, urban areas may be more in cultural diversity, and communities may have better opportunity to learn from setting such as school, church, work, home, or others [39]. Daughters from Tigray, Oromia, Somali, Benishangul Gumuz, SNNPR, and Gambella regions as well as Harari, Addis Ababa, and Dire Dawa towns had lower risk of FGM/C compared to the daughters in Afar region. A previous study conducted in Ethiopia supported this geographical disparity in daughters' FGM/C [24]. This may be due to the socio-cultural differences across the regions of the country such as ethnicity, economic development, and women's education.

As evidences revealed, the practice of FGM/C is associated with ethnic identity $[1,7,39]$. This study also found a significant association between ethnicity and the practice of $\mathrm{FGM} / \mathrm{C}$. As the findings of this study revealed, the girls in the Ethnicities of Somalie, Amhara, Oromo, Sidama Guragie, and Siltie had lower risk of having $\mathrm{FGM} / \mathrm{C}$ as compared to the girls in the ethnic group of Afar. This could be explained in that ethnicity may be a proxy for shared norms related to marriageability, sexual restraint, or other shared values [39]. Hence, this may suggest a call for targeted intervention programs to reduce or eliminate FGM/C.

This study also identified that higher proportion of the community with regular media exposure lowers the risk of $\mathrm{FGM} / \mathrm{C}$ in daughters by $30 \%$ as compared to the lower proportion of the community with regular media exposure. This may be due to the fact that media exposure has an important role in disseminating health information; and communities who have media exposure are more likely to have information on the risks of FGM/C practice.

In this study, the results should be interpreted cautiously since it requires an understanding that not all girls have reached their final cutting status; some of the girls who are not cut yet may still be cut in the future. Applying both spatial and non-spatial statistical methods for a more comprehensive and sound analysis was the strength of this study. However, girls from the EAs with no the geographical coordinates were not included in in this analysis and this may affect the results of the study including the generalizability. Hence, it could be mentioned as the limitation of the study.

\section{Conclusion}

In conclusion, the spatial distribution of FGM/C among girls in Ethiopia exhibits a clustered pattern. FGM/C hotspots were detected in Afar, Amhara, Tigray, Benishangul Gumuz, Oromia, SNNPR and Somali regions including Dire Dawa Town. Both individual and community level factors play a significant role in the practice of FGM/C among girls, which accounted for $83 \%$ variation across the communities. Older maternal age, lack of maternal education, maternal circumcision, better wealth index, higher number of living children, regular media exposure, perceived religious believes to FGM/C, women's opinion towards the practice of FGM/ $\mathrm{C}$ were statistical significant individual-level factors associated with the daughters' FGM/C. Whereas, place of residence, geographical region, ethnicity, and community media exposure were the community level factors associated with the practice of FGM/C among daughters. Hence, it is good if the federal ministry of health of Ethiopia and other concerned reproductive health programmers give priority for the FGM/C hotspots identified in this study. Furthermore, elimination of FGM/C requires integrated interventions both at individual and community levels: improving women's education, promoting media utilization, education of women on religious believes to $\mathrm{FGM} / \mathrm{C}$, and changing their attitudes towards the practice of $\mathrm{FGM} / \mathrm{C}$, and improving the households' wealth status. 


\section{Abbreviations}

AOR: adjusted odds ratio; Cl: confidence intervals; DHS: demographic and health survey; DIC: Deviance information criterion; EAs: Enumeration areas; EDHS: Ethiopian demographic and health survey; FGM/C: Female genital mutilation/cutting; GIS: geographic information system; ICC: intracluster correlation; LLR: Log likelihood ratio; MOR: median odds ratio;

PCV: proportional change in variance; PHC: population and housing census; SD: standard deviation; SNNPR: Southern Nations, Nationalities, and People Region; WHO: world health organization

\section{Acknowledgements}

The authors would like to thank the DHS program for their permission to download and use the 2016 EDHS datasets.

\section{Consent to publish}

Not applicable.

\section{Authors' contributions}

$\Pi$ conceived the study, conducted the statistical analysis and interpretation, and drafted the manuscript. MA and EW assisted the data management, statistical analysis and interpretation of results, reviewed the manuscript and did the final editing. All of the authors read and approved the final version of the manuscript.

\section{Funding}

The authors have no support or funding to report.

\section{Availability of data and materials}

The datasets used for this are available in the DHS program repository, (https://www.dhsprogram.com/data/dataset_admin) to all registered users.

\section{Ethics approval and consent to participate}

Ethical approval was obtained from the ethical review committee of the school of Public Health of the Bahir Dar University and the ICF International Institutional Review Board. The data has been used only for this registered research and it could not be passed on to other researchers.

\section{Competing interests}

The authors declare that they have no competing interests.

\section{Author details}

${ }^{1}$ Public Health Emergency Management (PHEM) Directorate, Amhara Public Health Institute (APHI), Bahir Dar, Ethiopia. ${ }^{2}$ School of Public Health, College of Medicine and Health Sciences, Bahir Dar University, Bahir Dar, Ethiopia.

\section{Received: 20 February 2020 Accepted: 13 January 2021}

Published online: 21 January 2021

\section{References}

1. World Health Organization, Eliminating female genital mutilation: an interagency statement. 2008, UNAIDS, UNDP, UNECA, UNESCO, UNFPA, UNHCHR, UNHCR, UNICEF, UNIFEM: Switzerland, Geneva.

2. United Nations, Declaration on the Elimination of Violence against Women. Resolution A/RES/48/104. 1990. p. 6-8.

3. World Health Organization, Global strategy to stop health-care providers from performing female genital mutilation. 2010, UNAIDS, UNDP, UNFPA, UNICEF, UNHCR, UNIFEM, WHO, FIGO, ICN, IOM, WCPT, WMA, MWIA: Geneva, Switzerland.

4. Bjälkander $\mathrm{O}$, et al. Health complications of female genital mutilation in Sierra Leone. Int J Women's Health. 2012;4:321-31.

5. Mgbako C, et al. Penetrating the silence in Sierra Leone: a blueprint for the eradication of female genital mutilation. Harvard Human Rights Journal. 2010;23:11.

6. UNICEF, At least 200 million girls and women alive today living in 30 countries have undergone FGM, 2018. Available at [https://data.unicef.org/ topic/child-protection/female-genital-mutilation]

7. UNICEF, Female genital mutilation/cutting: a global concern. 2016: New York.

8. Kandala N-B, et al. Secular trends in the prevalence of female genital mutilation/cutting among girls: a systematic analysis. BMJ Glob Health. 2018;3(5):e000549.
9. Central Statistical Agency [Ethiopia] and ORC Macro. Ethiopia demographic and health survey 2005. Addis Ababa, Ethiopia and Calverton, Maryland, USA: Central Statistical Agency and ORC Macro; 2006.

10. Central Statistical Agency - CSA/Ethiopia and ICF, Ethiopia Demographic and Health Sruvey 2016. 2017, CSA and ICF: Addis Ababa, Ethiopia.

11. Jones S, Ehiri J, Anyawu E. Female genital mutilation in developing countries: an agenda for public health response. Eur J Obstet Gynecol Reprod Biol. 2004;116:144-51.

12. Rushwan H. Female genital mutilation: a tragedy for women's reproductive health. Afr J Urol. 2013;19(3):130-3.

13. Federal Democratic Republic of Ethiopia and Ministry of Women Children and Youth, National Costed Roadmap to End Child Marriage and FGM/C 2020-2024. August 2019: Addis Ababa, Ethiopia.

14. Bogale D, Markos D, Kaso M. Prevalence of female genital mutilation and its effect on women's health in bale zone, Ethiopia: a cross-sectional study. BMC Public Health. 2014;14:1076.

15. Luseno W, et al. Assessing the value of climate forecast information for pastoralists: evidence from southern Ethiopia and northern Kenya. World Dev. 2003;31(9):1477-94.

16. Mohamud M, Kaba M, Tamire M. Assessment of Barriers of Behavioral Change to Stop Fgm Practice among Women of Kebri Beyah District, Somali Regional State, Eastern Ethiopia. Global Journals Inc. 2016;16(6).

17. Oljira T, Assefa N, Dessie $Y$. Female genital mutilation among mothers and daughters in Harar, eastern Ethiopia. Int J Gynecol Obstet. 2016; 135(3):304-9.

18. Shiferaw, D., et al., Prevalence and associated factors of female genital mutilation among high school students in Dale Wabera Woreda, Oromia Regional State, Ethiopia. international journal of medicine and medical science, 2017. 9

19. Yirga WS, et al. Female genital mutilation: prevalence, perceptions and effect on women's health in Kersa district of Ethiopia. Int J Women's Health. 2012:4:45-54.

20. Jackson $\mathrm{M}$, et al. Comparison of tests for spatial heterogeneity on data with global clustering patterns and outliers. Int J Health Geogr. 2009;6(55):8-55.

21. Song, C. and M. Kulldorff, Power evaluation of disease clustering tests. Int J Health Geogr. , 2003. 2(1).

22. Kulldorff M, Tango T, Park P. Power comparisons for disease clustering tests. Computational Statistics and Data Analysis. 2003:42(4):665-84.

23. Kulldorff M, Nagarwalla N. Spatial disease clusters: detection and inference Stat Med. 1995;14:799-810.

24. Setegn T, Lakew Y, Deribe K. Geographic variation and factors associated with female genital mutilation among reproductive age women in Ethiopia: a National Population Based Survey. PLoS One. 2016;11(1):e0145329.

25. Federal Minstry of Health, Ethiopian Growth and Transformation Plan. 2010 2015: Addis Ababa, Ethiopia.

26. Kulldorff M. and Information Management Services, Inc. SaTScan ${ }^{\mathrm{TM}}$ v9.6: Software for the spatial and space-time scan statistics. [www.satscan.org], 2018

27. Anselin L, Getis A. Spatial statistical analysis and geographic information systems. Ann Reg Sci. 1992;26(1):19-33.

28. Kulldorff M. SaTScanTM user guide for version 9.6March, 2018. http://www. satscan.org/.

29. Bernoulli, Discrete Poisson and Continuous Poisson Models: Kulldorff M. A spatial scan statistic. Communications in Statistics: Theory and Methods, 26: 1481-1496, 1997. [https://www.satscan.org/papers/k-cstm1997.pdf].

30. Akaike H. A new look at the statistical model identification. IEEE Trans Autom Control. 1974:19:716-23.

31. Merlo J, et al. A brief conceptual tutorial of multilevel analysis in social epidemiology: using measures of clustering in multilevel logistic regression to investigate contextual phenomena. J Epidemiol Community Health. 2006 60(4):290-7.

32. Austin PC, Stryhn H, Leckie G, Merlo J. Measures of clustering and heterogeneity in multilevel Poisson regression analyses of rates/count data. Stat Med 2018;37:572-589. https://doi.org/https://doi.org/10.1002/sim.7532.

33. ICF, 2012. The DHS Program Mobile App. Funded by USAID (Version 3.7.1) Computer software. Retrieved from http://itunes.apple.com. [Accessed January, 01, 2019]

34. Ministry of Health and Population/Egypt, El-Zanaty and Associates/ Egypt, and ICF International. Egypt demographic and health survey 2014. Cairo, Egypt: Ministry of Health and Population and ICF International; 2015 
35. Kenya National Bureau of Statistics, et al., Kenya Demographic and Health Survey 2014. 2015: Rockville, MD, USA.

36. Chad Demographic and Health Survey. Rockville. Maryland, USA: INSEED, MSP et ICF International; 2014-2015.

37. Ministry of Health, C.D.G.E, et al., Tanzania Demographic and Health Survey and Malaria Indicator Survey 2015-2016. 2016, MoHCDGEC, MoH, NBS, OCGS, and ICF: Dar es Salaam, Tanzania.

38. Achia, T.N. Spatial modelling and mapping of female genital mutilation in Kenya. BMC Pub Health. 2014;14:276. https://doi.org/10.1186/1471-2458-14276.

39. Shell-Duncan, B., D. Gathara, and Z. Moore, Female Genital Mutilation/ Cutting in Kenya: Is Change Taking Place? 2017, University of Washington, Population Council: Nairobi, Kenya.

40. Hayes R. Female genital mutilation, fertility control, Women's roles, and the Patrilineage in modern Sudan. Am Ethnol. 1975;2(4):617-33.

41. Hayford S. Conformity and change: community effects on female genital cutting in Kenya. J Health Soc Behav. 2005:46(2):121-40.

42. Kennedy J. Circumcision and excision in Egyptian Nubia. Man. 1970;5:175-91.

43. Masho S, Matthews L. Factors determining whether Ethiopian women support continuation of female genital mutilation. Int I Gynecol Obstet. 2009;107(3):232-5.

44. Sagna ML. Gender differences in support for the discontinuation of female genital cutting in Sierra Leone, culture, Health \& Sexuality. An International Journal for Research, Intervention and Care. 2014;16(6):603-19.

45. United Nations Children's Fund, Female Genital Mutilation/Cutting: A statistical overview and exploration of the dynamics of change. 2013: UNICEF, New York.

46. Gruenmaum E. The female circumcision controversy: an anthropological perspective. Philadelphia: University of Philadelphia press; 2001.

\section{Publisher's Note}

Springer Nature remains neutral with regard to jurisdictional claims in published maps and institutional affiliations.

Ready to submit your research? Choose BMC and benefit from:

- fast, convenient online submission

- thorough peer review by experienced researchers in your field

- rapid publication on acceptance

- support for research data, including large and complex data types

- gold Open Access which fosters wider collaboration and increased citations

- maximum visibility for your research: over $100 \mathrm{M}$ website views per year

At $\mathrm{BMC}$, research is always in progress.

Learn more biomedcentral.com/submissions 